\title{
Caretaker's perceptions, attitudes and practices regarding childhood febrile illness and diarrhoeal diseases among riparian communities of Lake Victoria, Tanzania
}

\author{
G.M. KAATANO ${ }^{1 *}$, A.I.S MURO ${ }^{2}$ and M. MEDARD ${ }^{2}$ \\ ${ }^{1}$ National Institute for Medical Research, Mwanza Research Centre, P.O. Box 1462, Mwanza, Tanzania \\ ${ }^{2}$ World Wide Fund for Nature, P.O. Box 63117, Dar es Salaam, Tanzania
}

\begin{abstract}
Understanding community perceptions and attitudes towards childhood illness is important in developing appropriate interventions. A cross sectional survey was therefore, conducted in a riparian community of Lake Victoria basin in Tanzania to determine caretakers' perception, attitudes and practices on childhood malaria and diarrhoeal diseases. Among 336 caretakers interviewed, 61.1\% (205) reported febrile illness in children within three months and $26.0 \%$ reported a diarrhoeal episode among children within two weeks before the survey. The majority of the respondents reported high fever (98.7\%) and prostration (53.7\%) as major symptoms of severe malaria. Convulsions were associated with high fever by only $13.7 \%$ of the respondents. Forty percent of the respondents attributed convulsions in children to either fever or malaria, and $24.4 \%$ correctly mentioned high fever or malaria. A health facility was the first point of care for childhood malaria for the majority (73\%) of the respondents. In diarrhoeal diseases, prostration-weakness $(67.7 \%)$ and dysentery (20.4\%) were commonly reported among the respondents. Typical symptoms of severe dehydration (sunken eyes, loss of skin turgor, dry tears) were poorly recognised as characteristics of severe diarrhoeal diseases. Over $85 \%$ of the respondents practiced appropriate dietary measures or increased fluid intake for a child who had diarrhoea. Use of anti-diarrhoea $(40.8 \%)$ and antibiotic medications $(34.8 \%)$ were common in the treatment of diarrhoeal diseases. It is important that health education emphasizing recognitions of danger signs/symptoms of malaria and diarrhoeal diseases and their management is strengthened among riparian communities in Lake Victoria basin.
\end{abstract}

Key words: Malaria, diarrhoea, knowledge, practices, caretakers, children, Tanzania

\section{Introduction}

Malaria and diarrhoeal diseases are among the most important cause of morbidity and mortality in children in Tanzania. About $93.6 \%$ of the population in Tanzania is living in areas of high malaria transmission (http://www.mrc.ac.za/maracrt). Malaria is a major cause of morbidity and mortality, particularly among pregnant women and young children. In Tanzania, malaria accounts for $50 \%$ of under-five deaths, and causes high morbidity accounting for $38-40 \%$ of outpatients and $50-54 \%$ of inpatients ( $\mathrm{MoH}, 2002)$. It has been estimated that on average there are about 0.7 and 0.6 episodes per child per year of clinical malaria and severe anaemia, respectively in underfive children (Menendez et al., 1997).

Globally, diarrhoeal diseases are also among the leading causes of morbidity and mortality in under-five children (WHO, 1990). Children less than five years of age have over 3 diarrhoeic episodes per year, and more than one-third of their deaths are associated with diarrhoea. It is estimated that 1.5 billion diarrhoeic episodes and 4 million deaths in children $<5$ years old occur in the world each year (Snyder \& Merson, 1982; Bern et al., 1992). Diarrhoeal diseases are ranked third after malaria and respiratory infections as a cause of death in underfive children in Tanzania (MoH, 2002). In Tanzania, the main aetiological agents for diarrhoea in children include Escherichia coli, Shigella spp., Giardia lamblia and rotavirus (Vargas et al., 2004).
Mushrooming of new settlements in Lake Victoria basin due to increased population and fish industries have resulted into pollution of lake water, which is the main $\mathrm{s}$ source of water for domestic use. This situation is likely to have resulted into the increase in some water-borne diseases among the inhabitants. Lake Victoria basin, which has an equatorial climate with regular seasonal rains, has stable malaria transmission though some epidemics have been reported in Muleba (Garay, 1998) and Bukoba districts (Ministry of Health, unpubl.). Malaria risk is likely to increase in the fishing villages and other lakeside communities because of increased mosquitobreeding sites and migrant populations, who are usually with low immunity. Poor sanitation practices and contamination of Lake Victoria waters may lead people to use unsafe water, which might cause an increase in diarrhoeal diseases among the riparian communities.

The success of malaria control strategies depends upon perceptions of malaria and people's treatment seeking behaviour. It is therefore, important to understand caretaker's perceptions, attitudes and practices regarding childhood malaria. Such information will be useful in developing strategies to enhance early diagnosis and treatment of malaria. Moreover, disease prevention and control in many communities in Tanzania start at the household level. Thus, the ability of caretakers to recognize danger signs of malaria and diarrhoeal diseases is an important factor for early home management or for seeking treatment at health facility (Patel et al., 1988). This study, therefore, was carried out to explore the perceptions, attitudes and practices 
of caretakers regarding diarrhoea and febrile illnesses in underfive children that may influence treatmentseeking behaviour, in selected districts in Lake Victoria basin of Tanzania.

\section{Material and Methods}

\section{Study area}

This study was carried out in Kagera, Mwanza and Mara Regions of north-western Tanzania. In each region, two districts were selected. They included: Bukoba and Muleba (Kagera), Sengerema and Geita (Mwanza) and Musoma and Tarime (Mara) in Lake Victoria basin of Tanzania. The area has two wet seasons in addition to regular conventional rains from the lake.

The study was conducted in selected village of Nyalwambu and Nyakalilo (Sengerema); Kasang'hwa and Bukondo (Geita), Kasheno and Kabare (Muleba), Mushozi and Kiilima (Bukoba), Kirongwe and Masonga (Tarime) and Bulinga and Kusenyi (Musoma).

Study villages were selected by multistage sampling where in each district two-cluster units were randomly selected starting with districts bordering the Lake Victoria as first stage. Then from these districts, two wards per district and two villages per ward (bordering the lakeshores) were randomly selected. In each village, two sub-villages were also randomly selected. In each sub-village, 100 participants in the ratio of $3: 3: 4$ for $<5$ years, $5-14$, and those $\geq 15$ years, respectively were randomly sampled.

In the selected villages, caretakers with children $<5$ years were interviewed using a structured questionnaire to obtain information on demographic characteristics, knowledge, attitudes and practices regarding febrile illness/malaria and diarrhoeal diseases in children. Knowledge on malaria causation, signs, symptoms, and prevention were explored. For diarrhoeal disease, knowledge on recognition of symptoms for severe diarrhoea and recommended fluids for rehydration therapy were explored. To assess practices regarding the management of childhood febrile illness/malaria and diarrhoeal diseases, caretakers who reported an episode of malaria within a period of threemonths and an episode of diarrhoea in the previous two weeks, were asked of the actions taken.

\section{Data analysis}

Data entry was done using Dbase IV (Borland International, Scotts Valley, California) and analysis was done by Stata version 4 (Stata Corp., College Station, Texas, USA).

\section{Results}

A total of 336 caretakers and their under-five children were recruited in the study. Over $65 \%$ of caretakers were in the 15-34 year age group. Majority of the respondents were biological mothers $(68 \%)$ whereas biological fathers accounted for only 19.1\%. Most $(82.4 \%)$ of caretakers had primary level of education. The majority $(85.9 \%)$ of the caretakers had stayed in the area for more than 10 years. Multiple sources of income accounted for the majority $(81.8 \%)$ of female caretakers (Table 1).

Table1: Socio-demographic characteristics of caretakers by region $(\mathrm{N}=336)$

\begin{tabular}{|c|c|c|c|c|c|}
\hline Variable & Variable category & Mwanza & Kagera & Mara & Total \\
\hline & & $N(\%)$ & $\mathbf{N}(\%)$ & $\mathbf{N}(\%)$ & $N(\%)$ \\
\hline \multirow[t]{4}{*}{ Age (in years) } & $15-24$ & $28(22.2)$ & $20(18.5)$ & $23(21.7)$ & $71(20.9)$ \\
\hline & $25-34$ & $48(38.1)$ & $53(49.1)$ & $50(47.2)$ & $151(44.4)$ \\
\hline & $35-44$ & $25(19.8)$ & $25(23.2)$ & $23(21.7)$ & $73(21.5)$ \\
\hline & $\geq 45$ & $25(19.8)$ & $10(9.3)$ & $10(9.3)$ & $24(7.1)$ \\
\hline \multirow[t]{3}{*}{ Relationship } & Biological mother & $76(60.3)$ & $83(76.9)$ & $74(69.8)$ & $233(68.5)$ \\
\hline & Biological father & $24(19.6)$ & $21(19.4)$ & $22(20.8)$ & $67(19.7)$ \\
\hline & Others & $26(20.6)$ & $4(3.7)$ & $10(9.5)$ & 40 (11.8) \\
\hline \multirow[t]{3}{*}{ Education } & No education & $26(20.6)$ & $22(20.4)$ & $12(11.3)$ & $60(17.6)$ \\
\hline & Primary & $90(71.4)$ & $82(75.9)$ & $82(77.4)$ & $254(74.7)$ \\
\hline & Secondary & $10(7.9)$ & $4(3.7)$ & $12(11.3)$ & $26(7.6)$ \\
\hline \multirow[t]{4}{*}{ Source of income } & Farming & $49(38.9)$ & $3(2.8)$ & $7(6.6)$ & $59(17.4)$ \\
\hline & Petty business & $9(7.1)$ & $2(1.9)$ & $1(0.9)$ & $12(3.5)$ \\
\hline & Livestock keeping & $5(4.1)$ & $0(0.0)$ & $0(0.0)$ & $5(1.5)$ \\
\hline & Fishing & $2(1.9)$ & $0(0.0)$ & $0(0.0)$ & $2(0.6)$ \\
\hline \multirow[t]{3}{*}{ Duration of residence } & $<5$ years & $10(7.9)$ & $6(5.5)$ & $6(5.7)$ & $22(6.4)$ \\
\hline & $5-10$ years & $18(14.3)$ & $8(7.3)$ & $0(0.0)$ & $26(7.6)$ \\
\hline & $>10$ years & $98(77.8)$ & $95(87.2)$ & $106(94.3)$ & $293(85.9)$ \\
\hline
\end{tabular}


Among the respondents, 61.1\% (205) reported an episode of febrile illness among under-five children during the three months prior to the survey. The overall incidence of reported febrile illness, two weeks prior and during the survey period, were $48.8 \%$ and $19.4 \%$, respectively. In addition, $26.0 \%$ reported a diarrhoeal episode in the prior 2 weeks and $12.8 \%$ of caretakers reported that a child was currently having diarrhoea. Eight percent of caretakers reported an vomiting or profuse vomiting (20\%) and convulsion (13.7\%) (Table 3).

The pattern of knowledge of the most severe illness episodes was similar in the districts, except for fewer caretakers in Tarime who reported prostration, profuse vomiting and convulsion. More than half $(56.3 \%)$ of caretakers attributed episodes of high fever to malaria, $16.3 \%$ to other causes such as supernatural forces, witchcraft, bad weather or avenging spirits. Majority of caretakers (73.8\%)

Table 2: Reported occurrence (\%) of febrile illness, diarrhoeal illness and blood in stool among underfives by districts $(\mathrm{N}=336)$

\begin{tabular}{|c|c|c|c|c|c|c|}
\hline \multirow[b]{2}{*}{ District } & \multicolumn{2}{|c|}{ Febrile illness } & \multicolumn{3}{|c|}{ Diarrhoea illness } & \multirow{2}{*}{$\frac{\text { Blood in stool }}{2 \text { weeks before }}$} \\
\hline & $\begin{array}{l}\text { During } \\
\text { the study }\end{array}$ & $\begin{array}{l}2 \text { weeks } \\
\text { before }\end{array}$ & $\begin{array}{l}3 \text { months } \\
\text { before }\end{array}$ & $\begin{array}{l}\text { During } \\
\text { the study }\end{array}$ & $\begin{array}{l}2 \text { weeks } \\
\text { before }\end{array}$ & \\
\hline Sengerema & 18.2 & 45.5 & 53.1 & 10.6 & 19.7 & 10.8 \\
\hline Geita & 28.3 & 50.8 & 60.6 & 15.5 & 28.3 & 16.7 \\
\hline Bukoba & 14.5 & 40.7 & 64.8 & 11.1 & 20.4 & 1.9 \\
\hline Muleba & 18.5 & 46.3 & 61.8 & 9.3 & 36.4 & 3.7 \\
\hline Musoma & 15.8 & 49.1 & 59.7 & 19.6 & 33.9 & 5.4 \\
\hline Tarime & 20.4 & 57.1 & 67.4 & 10.2 & 18.8 & 8.2 \\
\hline Total & 19.4 & 48.8 & 61.1 & 12.8 & 26.3 & 8.0 \\
\hline
\end{tabular}

episode of blood in stool among their children (Table 2).

Among 205 caretakers who reported their child to have a febrile illness episode, $38.6 \%$ reported severe illness. Among 80 caretakers admitted their children to have had severe febrile illness. Symptoms indicating severe febrile illness were mentioned to include high fever (98.7\%), prostration (53.7\%), reported to have taken their children to health facilities while a quarter practised self-medication using modern medicine. A few caretakers reported taking their children to traditional healers $(2.5 \%)$ or using local herbs $(6.5 \%)$ at home. The latter were much more observed in Muleba district (Table 3).

Majority $(86.4 \%$ of caretakers knew that malaria was transmitted through a bite of a mosquito. Other

Table 3: The proportion (\%) of caregivers on their knowledge of high fever/malaria symptoms, and treatment seeking behaviour $(\mathrm{N}=80)$

\begin{tabular}{|c|c|c|c|c|c|c|c|}
\hline Knowledge & Sengerema & Geita & Muleba & Bukoba & Tarime & Musoma & Total \\
\hline \multicolumn{8}{|l|}{$\begin{array}{l}\text { Severe } \\
\text { symptoms/sign }\end{array}$} \\
\hline High fever & 100 & 100 & 88.9 & 100 & 100 & 100 & 98.8 \\
\hline Prostration & 55.7 & 68.4 & 44.4 & 62.5 & 22.2 & 52.9 & 53.6 \\
\hline Vomiting/profuse vomiting & 27.8 & 21.1 & 44.4 & 12.5 & 11.1 & 5.9 & 20.0 \\
\hline Convulsion & 27.8 & 15.8 & 11.1 & 12.5 & 0 & 5.9 & 13.7 \\
\hline Others & 27.8 & 26.3 & 11.1 & 12.5 & 44.4 & 26.2 & 26.2 \\
\hline \multicolumn{8}{|l|}{ Cause of high fever } \\
\hline Malaria & 72.2 & 57.9 & 33.3 & 50.0 & 55.6 & 52.9 & 56.3 \\
\hline Other & 16.7 & 21.1 & 22.2 & 12.5 & 11.1 & 11.8 & 16.3 \\
\hline Do not know & 11.1 & 21.1 & 44.4 & 37.5 & 33.3 & 35.3 & 27.5 \\
\hline \multicolumn{8}{|l|}{ Treatment seeking } \\
\hline Health facilities & 72.2 & 84.2 & 55.6 & 75.0 & 77.8 & 70.6 & 73.8 \\
\hline Self-medication & 27.8 & 21.1 & 22.2 & 25.0 & 22.2 & 29.4 & 25.0 \\
\hline Others & 11.4 & 0 & 22.2 & 12.5 & 0 & 0 & 6.5 \\
\hline Traditional Healers & 0 & 0 & 22.2 & 0 & 0 & 0 & 2.5 \\
\hline
\end{tabular}


respondents associated malaria with cold weather, witchcraft and wet conditions. Sixty one percent of caretakers reported to be aware of $\mathrm{NGAO}^{\circledR}$ (insecticide commonly used to treat mosquito nets in Tanzania), of those, $73.1 \%$ reported correctly that it is used to treat nets. While $15.9 \%$ of caretakers did not know its use, 3.5\% thought it was for protecting against mosquito by bathing (Table 4). Sulfadoxinepyrimethamine $(32.9 \%)$, chloroquine $(31.4 \%)$, paracetamol (1.3\%) and acetyl salicylic acid (aspirin) $(1.1 \%)$ were commonly reported as drugs used in the treatment of malaria.

The proportion of respondents with knowledge of an insecticide used to treat mosquito nets (NGAO ${ }^{\circledR}$ ) was $84.8 \%, 70.0 \%, 61.1 \%, 33.3 \%, 40.8 \%$ and $67.8 \%$ in Sengerema, Geita, Muleba, Bukoba, Tarime and Musoma, respectively. The respective proportion of respondents with knowledge on correct use of NGAO ${ }^{\circledR}$ was $84.4 \%, 67.4 \%, 56.1 \%, 36.8 \%$, $95.0 \%$ and $65.8 \%$.

About half $(50.7 \%)$ of the respondents didn't know the cause of convulsions. About $40 \%$ of the respondents attributed convulsions in children to either fever or malaria, and $22.4 \%$ correctly mentioned severe fever or malaria as the cause (Table 4). Other causes locally known as michango or nzoka, supernatural forces and extreme coldness or wind were reported by $9.5 \%$. Majority $(80.9 \%)$ of the respondents reported that taking their children to health facilities for treatment of febrile convulsion illness would be their first step. Others reported traditional healers $(10.8 \%)$, self-medication using local herbs $(5.1 \%)$ and tepid sponging $(0.9 \%)$ as their first action for managing convulsions in children. It is worth noting that, consultation with traditional

Table 4: Knowledge on the of causes of malaria and convulsion, and treatment seeking behaviour among caretakers $(\mathbf{N}=\mathbf{3 3 5})$

\begin{tabular}{|c|c|c|c|c|c|c|c|}
\hline Knowledge/Practice & Sengerema & Geita & Muleba & Bukoba & Tarime & Musoma & Total \\
\hline \multicolumn{8}{|l|}{ Malaria transmission } \\
\hline Mosquito bites & 90.9 & 71.7 & 83.3 & 92.6 & 73.3 & 94.6 & 86.4 \\
\hline \multicolumn{8}{|l|}{ Cause of convulsion } \\
\hline High fever/severe malaria & & & 18.9 & & & 33.3 & 22.4 \\
\hline Malaria illness & 66.7 & 21.7 & 41.5 & 48.1 & 16.3 & 36.8 & 39.6 \\
\hline Others causes & 12.2 & 16.7 & 5.7 & 7.4 & 6.4 & 7.0 & 9.5 \\
\hline \multicolumn{8}{|l|}{ Treatment seeking } \\
\hline Health facilities & 71.2 & 82.4 & 82.0 & 85.2 & 81.6 & 85.5 & 80.9 \\
\hline Traditional healer & 22.7 & 9.8 & 8.0 & 7.4 & 8.2 & 5.4 & 10.8 \\
\hline \multicolumn{8}{|l|}{ Self medication by } \\
\hline local herbs & 3.0 & 7.8 & 8.0 & 5.6 & 2.0 & 5.6 & 5.1 \\
\hline Tepid sponging & 1.5 & 0 & 0 & 0 & 2.0 & 5.5 & 0.9 \\
\hline
\end{tabular}

Table 5: Treatment seeking and feeding practices among caretakers of under-fives children with diarrhoea

\begin{tabular}{|c|c|c|c|c|c|c|c|}
\hline \multirow{2}{*}{ *Steps taken } & \multirow[t]{2}{*}{ Sengerema } & \multirow[t]{2}{*}{ Geita } & \multirow[t]{2}{*}{ Muleba } & \multirow[t]{2}{*}{ Bukoba } & \multirow[t]{2}{*}{ Tarime } & \multicolumn{2}{|c|}{ Musoma } \\
\hline & & & & & & & \\
\hline Health facility & 53.9 & 52.9 & 20.0 & 54.6 & 22.2 & 36.8 & 39.3 \\
\hline Sugar-salt solution & 79.9 & 58.8 & 25.0 & 18.2 & 11.1 & 31.8 & 36.8 \\
\hline Anti-diarrhoea & 30.8 & 35.3 & 40.0 & 18.2 & 22.2 & 21.1 & 29.2 \\
\hline Antibiotics & 23.1 & 11.8 & 15.0 & 18.2 & 0 & 10.5 & 13.5 \\
\hline $\begin{array}{l}\text { Traditional healers } \\
\text { *Home fluids/feeding }\end{array}$ & 23.1 & 5.9 & 10.0 & 0 & 33.3 & 15.8 & 13.5 \\
\hline Normal & 23.1 & 52.9 & 75.0 & 45.6 & 44.4 & $52 . .6$ & 51.7 \\
\hline Increased & 69.2 & 29.4 & 20.0 & 54.6 & 22.2 & 31.6 & 35.6 \\
\hline Decreased/stopped & 2.7 & 17.7 & 5.0 & 0 & 33.3 & 15.8 & 12.6 \\
\hline${ }^{* *}$ Continued B/F & 100 & 50.0 & 25.0 & 60.0 & 100.0 & 100.0 & 53.3 \\
\hline *** Stopped/less food & 23.1 & 29.4 & 5.0 & 18.2 & 0 & 5.3 & 13.8 \\
\hline
\end{tabular}

${ }^{*} \mathrm{~N}=89$ children with diarrhoea; ${ }^{* *} \mathrm{~N}=30$ children breast fed before diarrhoea; ${ }^{* \star \star} \mathrm{N}=86$ children, excluding 3 children not yet weaned; BF- breast feeding 
healers for treatment of convulsion among caretakers was much higher in Sengerema (22.7\%).

Regarding first steps taken during diarrhoea episode, $60.7 \%$ used some form of treatment at home and $39.3 \%$ took their sick children to health facilities. Oral rehydration salt (ORS) (36.8\%) and antidiarrhoeal medication (29.5\%) were the commonly reported treatments given (Table 5). More caretakers in Sengerema, Geita and Bukoba districts reported sending their children with diarrhoea to heath facility and using salt sugar solution than those in other districts. Consultation with traditional healers (13.5\%) and self-medication by giving some other drugs mainly antibiotics $(13.5 \%)$ were rarely reported as first action. Generally, treatment seeking practices were similar in all districts except that in Tarime and Musoma districts the caretakers were less likely to treat diarrhoea with drugs and much more likely to use local herbs or attend traditional healers. Among fluids. More caretakers in Tarime district stopped or decreased giving fluids to children with diarrhoea. Majority of caretakers ( $86.2 \%$ ) who were giving their children semi-solid or solid food prior to onset of diarrhoea continued giving normal amount of food intake or increased amount of food intake. Feeding pattern of semi solid or solid foods were relatively the same in all districts except that a higher proportion of caretakers in Sengerema and Geita districts reduced food or stopped feeding solid foods during diarrhoea episode.

There was no difference regarding knowledge of symptoms of diarrhoea among districts except in Sengerema where fewer caretakers mentioned sunken eyes and failure to take fluids as signs for severe diarrhoea (Table 6). Feeding their children with boiled water, proper hand washing before feeding the child and watching/protecting their children from eating contaminated foodstuffs were commonly reported by

Table 6: Perceived danger symptoms/signs, preventive measures and recommended fluids reported by caretakers of children with diarrhoeal diseases $(\mathrm{N}=335)$

\begin{tabular}{|c|c|c|c|c|c|c|c|}
\hline Perception & Sengerema & Geita & Muleba & Bukoba & Tarime & Musoma & Total \\
\hline \multicolumn{8}{|l|}{ Danger symptoms/sign } \\
\hline Prostration (weakness) & 54.6 & 71.7 & 59.3 & 73.6 & 75.0 & 75.0 & 67.7 \\
\hline Dysentery & 15.1 & 20.0 & 25.9 & 22.6 & 8.3 & 30.4 & 20.5 \\
\hline Profuse vomiting & 19.7 & 5.0 & 9.3 & 13.2 & 10.4 & 10.7 & 11.6 \\
\hline Sunken eyes & 3.0 & 5.0 & 11.1 & 13.2 & 4.2 & 5.4 & 6.8 \\
\hline Failure of fluid intake & 0.0 & 6.7 & 9.3 & 5.7 & 10.4 & 7.1 & 6.2 \\
\hline Loss of skin turgor & 0.0 & 1.7 & 1.9 & 1.9 & 0.0 & 5.4 & 1.8 \\
\hline \multicolumn{8}{|l|}{ Preventive measures } \\
\hline Feeding boiled water & 75.8 & 44.1 & 68.5 & 57.7 & 44.9 & 46.4 & 56.4 \\
\hline Hand washing before feeding & 75.8 & 44.1 & 48.1 & 39.6 & 38.8 & 43.6 & 49.4 \\
\hline \multicolumn{8}{|l|}{ Protect child from eating } \\
\hline contaminated staff & 77.3 & 35.6 & 37.0 & 41.5 & 32.7 & 30.4 & 43.6 \\
\hline Proper child feeds storage & 62.1 & 15.2 & 26.0 & 13.2 & 14.3 & 14.3 & 25.5 \\
\hline \multicolumn{8}{|l|}{ Proper washing of child s } \\
\hline feeding utensils & 54.6 & 18.6 & 13.0 & 18.9 & 16.3 & 10.7 & 23.1 \\
\hline \multicolumn{8}{|c|}{ Appropriate treatment for diarrhoea in children } \\
\hline Oral rehydration therapy & 87.9 & 65.0 & 50.0 & 66.7 & 38.8 & 69.6 & 64.3 \\
\hline Antidiarrhoeals & 59.1 & 46.7 & 46.3 & 13.0 & 33.3 & 41.1 & 40.7 \\
\hline Antibiotics & 42.4 & 28.3 & 22.2 & 37.0 & 42.9 & 37.5 & 35.1 \\
\hline Sweetened fluids/drinks & 34.9 & 11.7 & 20.4 & 14.8 & 14.3 & 12.5 & 18.6 \\
\hline Other salt free fluids & 9.1 & 5.0 & 7.4 & 1.8 & 0 & 1.8 & 18.6 \\
\hline
\end{tabular}

30 mothers who were breast-feeding prior to the onset of diarrhoea episode, overall $53.3 \%$ of them continued breast-feeding their children, with Tarime, Musoma and Sengerema reporting $100 \%$ continued breastfeeding (Table 5).

Provision of fluids to children with diarrhoea was one of the actions taken by caretakers. Half of the children with diarrhoea were given 'normal' fluid intake and $35.2 \%$ received an increased amount of caretakers as measures taken to protect their children against diarrhoea.

\section{Discussion}

The prevalence of reported febrile illness observed in this study was higher than that reported in the recently carried out demographic health survey in rural communities of Tanzania (TDHS, 2004). Although, 
the sample sizes of the two studies were different, this high prevalence suggests higher levels of transmission of malaria in areas of the Lake Victoria basin. It has been established that in endemic areas most febrile illness among under-five children is due to malaria (Muller et al., 2003). However, the possibility of the presence of other infectious diseases like Acute Respiratory Infections (ARI) cannot be ignored. In Tanzania, acute respiratory infections contributes to $14.2-15.1 \%$ of outpatients and $3.1-4.6 \%$ of inpatients among the $<5$ years old children (Kitua, 2003). According to health facility based morbidity records (data not shown), ARI accounted for $22.0 \%$ of all attended cases in eleven surveyed health facilities in the study area.

Over fifty percent of caretakers whose children presented with fever, attributed it to malaria. This indicates their recognition that fever is often associated with malaria. Since in malaria endemic areas all patients with fever are treated presumptively as malaria cases, these findings have important implications in the management of malaria illness. It is of concern that other febrile children whose caretakers did not suspect malaria may have gone untreated at the primary care level. It is important that laboratory capacities at health facilities are strengthened for confirmatory purposes.

The recognition of convulsion as a symptom of severe malaria among caretakers who reported severe malaria among the children in the last three months was even lower. This could be attributed to the fact that people consider childhood convulsions and malaria to be due to different causes, as reported by Patel et al. (1988). Mwenesi et al. (1995), also revealed that convulsive illness in Kenya coastal areas is often regarded as a separate disease and not linked to malaria and is considered to be well manageable by traditional healers. Therefore, the link between convulsions and malaria also needs to be emphasized in health education/health promotion programmes. Health education should specifically focus on the fact that convulsions are treatable by modern medicine.

Although the Ministry of Health has withdrawn chloroquine as first line drug for treating malaria since 2001, many people still regard it as a drug of choice for malaria treatment. Sulfadoxine-pyrimethamine, which is currently the first line antimalarial drug, was not well known by most of the caretakers. It is also of high concern that in an area with such a high rate of malaria endemicity, there were some individuals who used antipyretics and analgesics for the treatment of malaria. This observation clearly shows that there is a need of providing information at the community level, about the drug policy change regarding antimalarial drugs.

The prevalence of diarrhoea during our survey was higher than the $8.9 \%$ that was found in the Lake zone during an earlier demographic survey (THDS, 2004). Poor sanitation and lack of safe water could contribute to these high rates. Many people along the lake rely on lake water for domestic use, which is generally unsafe due to increased pollution and down stream effects from the Lake Victoria shore settlements. Medard et al. (2002) observed that in Mwanza and Mara regions lake water, deep/shallow wells, springs, rivers, rainwater and ponds were sources of supplies for drinking whereas in Kagera, the spring and rivers were common sources. It was also noted that most households did not boil water from deep/shallow wells or springs. The high prevalence of blood in stool that was observed could be contributed to intestinal schistosomiasis that is endemic in the study area (Outwater \& Mpangala, 2005).

The proportion of caretakers who stopped breastfeeding during episodes of diarrhoea was much higher in this study than that reported elsewhere (WHO, 1994). One possible explanation for this could be the cultural beliefs (Ahmed et al., 1994) that breastfeeding of a child with diarrhoea may exacerbate the severity of the disease. This belief is more pronounced when the mother is suspected to be pregnant. On the other hand, the majority of children who were on semi-solid or solid foods received normal amount of food or the amount of food was increased. Although there are some indications of improvement in feeding practices and administration of fluids during diarrhoea, there is a need for enhancing knowledge and practices among caregivers in this area.

Many caretakers considered giving of antibiotics and/or anti-diarrhoea drugs as appropriate treatment of acute diarrhoea. However, such antibiotics are not recommended for treating normal acute diarrhoea, unless when dysentery is suspected (WHO, 1994). It is important to note that such an attitude of preferring using antibiotics may lead to widespread antibiotic resistance and diversion of attention from appropriate treatment of diarrhoea. The use of sweetened fluids like soft drinks were also cited as appropriate treatment for diarrhoea by a substantial number of caretakers though it is not advisable because these can worsen the diarrhoea. Therefore action has to be taken to control irrational use of antibiotics, control availability of antidiarrhoeal medications and to encourage use of appropriate fluids. 
Most caretakers did not recognize danger signs/ symptoms of severe dehydration, such as profuse vomiting, sunken eyes, failure of fluid intake, and loss of skin turgor. Understanding of such danger signs is important because it can enable one to respond promptly by giving oral fluids or to seek treatment at health facilities. This indicates the need for health education to the communities on symptoms and signs of severe dehydration so that they promptly seek treatment.

The use of oral rehydration therapy observed in this study is comparable to findings of the recent demographic survey (THDS, 2004). In most developing countries ORS usage is still low. For instance, household survey in 35 developing countries in 1990/92 showed a low ORS use rate $(0.8 \%-56 \%)$ with Tanzania having $36.9 \%$. In view of poor access to ORS in most developing countries WHO (1994) is emphasizing increase of the total fluid intake using fluids that are available in most homes and that mothers consider safe and acceptable for children with diarrhoea.

Although mothers/caretakers of under-fives had some knowledge on some aspects of febrile illness and diarrhoeal diseases they need to be educated on the recognition of their danger symptom/signs and appropriate management.

\section{References}

Ahmed, I.S., Eltom, Z.A., Kaprar, Z.A. \& Gibril, A.R. (1994) Knowledge, attitude and practices of mother regarding diarrhoea among children in Sudanese rural community. East African Medical Journal 71, 716-719.

Bern, C., Jimenez, J., de Zoysa, I. \& Glass, R.I. (1992) The magnitude of global problem of diarrhoeal disease: a ten-year update. Bulletin of the World Health Organization 70, 705-714.

Garay, J. (1998) Epidemiological survey and situation analysis: malaria epidemic in Nshamba Division, Muleba District. Spain, MSF, 47pp.

Kitua, A.Y. (2003) Malaria control in the context of integrated management of childhood illness in Tanzania: the challenges ahead. Tanzania Health Research Bulletin 5, 1-4.

Medard, M., Geheb, K., Mlahagwa, E., Kabati, M., Komba, D., Msunga, D., Zenge, B., Wabeya, U. \& Ngussa, D. (2002) An assessment of the nutritional status of fishing and farming communities in Tanzania's Lake Victoria basin. In Geheb, K. (ed.): Report of the LVFRP Nutrition Survey. LVFRP Technical Document No. 18. Jinja, Uganda, Socio-economic Data Working Group of the Lake Victoria Fisheries Research Project. Pp $30-48$.
Menendez, C., Kahigwa, E., Hirt, R., Vounatsou, P., Aponte, J.J., Font, F., Acosta, C.J., Schellenberg, D.M., Galindo, C.M., Kimario, J., Urassa, H., Brabin, B., Smith, T.A., Kitua, A.Y., Tanner, M., \& Alonso, P.L. (1997) Randomised placebocontrolled trial of iron supplementation and malaria chemoprophylaxis for prevention of severe anaemia and malaria in Tanzanian infants. Lancet 350, 844-850.

MoH (2002) Health Statistics Abstract 2002 Vol 1 Morbidity and Mortality Data. Ministry of Health, United Republic of Tanzania.

Muller, O., Traore, C., Becher, H. \& Kouyate, B. (2003) Malaria morbidity, treatment-seeking behaviour, and mortality in a cohort of young children in rural Burkina Faso. Tropical Medicine and International Health 8, 290-296.

Mwenesi, H., Harphan, T. \& Snow, R.M. (1995) Childhood malaria treatment practices among mothers in Kenya. Social Science \& Medicine 50, 1271-127.

Outwater, A.H. \& Mpangala, E. (2005) Schistosomiasis and US Peace Corps volunteers in Tanzania. Journal of Travel Medicine 12, 265269.

Patel, V.L., Eisemon, T.O. \& Arocha, J.F. (1988) Causal reasoning and the treatment of diarrhoeal diseases by mothers in Kenya. Social Science \& Medicine 159, 1061.

Snow, R.W., Craig, M., Deichmann, U. \& Marsh, K. (1999) Estimating mortality, morbidity and disability due to malaria among Africa's nonpregnant population. Bulletin of the World Health Organization 77, 624-640.

Snyder, S.D. \& Merson, M.H. (1982) The magnitude of the global problem of acute diarrhoeal disease: a review of active surveillance data. Bulletin of the World Health Organization 60, 605-613.

TDHS (2004) Tanzania Demographic and Health Survey. National Bureau of Statistics, United Republic of Tanzania.

Vargas, M., Gascon, J., Casals, C., Schellengberg, D., Urassa, H., Kahigwa, E., Ruiz, J. \& Vila, J. (2004) Etiology of diarrhea in children less than five years of age in Ifakara, Tanzania. American Journal of Tropical Medicine and Hygiene 70, 536-539.

WHO (1990) Programme for the Control of Diarrhoeal Disease: A Manual for the Treatment of Diarrhoeal Diseases. World Health Organization, WHO/CDD/SER/80.2 Rev.2.

WHO (1994) Programme for the Control of Diarrhoeal Disease. Ninth Programme Report 1992-1993(WHO/CDD/94. 46) 